\title{
LONG-TERM RESULTS OF THE EVANS PROCEDURE FOR LATERAL INSTABILITY OF THE ANKLE
}

\author{
OLLI KORKALA, PEKKA TANSKANEN, JORMA MÄKIJÄRVI, TUOMAS SORVALI, \\ MATTI YLIKOSKI, JUSSI HAAPALA
}

From Lahti City Hospital, Finland

\begin{abstract}
We studied the late outcome of $\mathbf{4 0}$ ankles (from a consecutive series of $\mathbf{4 2}$ ) treated by a modified Evans procedure. The peroneus brevis tendon was used to fashion a static tenodesis. All the patients had suffered from persistent lateral instability following an ankle sprain. The follow-up period was between nine and 12 years.

Excellent or good results were achieved in 33 ankles $(82.5 \%)$, three had a fair result, and four were poor. The clinical results were matched by the radiographic results which showed significant talar tilt or anterior talar translation in only three ankles. The functional result showed no positive correlation with the stressradiographic analysis.

We concluded that this modification of the Evans operation gives satisfactory long-term results, which show little change from the good results at 24 to 35 months reported in an earlier paper from our department.
\end{abstract}

Persistent lateral instability is a common complication of severe ankle sprains left untreated or treated inadequately. In addition to recurrent sprains, swelling and pain are frequent, especially after exercise. Often, a sort of functional instability is manifested by fear of the ankle giving way (Freeman 1965), and this is more common in joints treated by conservative means rather than by primary operation (Korkala et al 1987).

Sometimes late instability can be treated by suture of the torn lateral ligaments (Broström 1966), but most surgeons prefer a tenodesis or reconstruction by a free or partly attached autogenous tendon graft. In most techniques the peroneus brevis tendon is used as a ligament substitute (Nilsonne 1932; Elmslie 1934; Watson-Jones 1952; Evans 1953; Weber and Hupfauer 1969; Snook, Chrisman and Wilson 1985).

While the short-term results of these reconstructions are satisfactory in most cases, it has been suggested that

O. Korkala, MD, Docent in Orthopaedics and Trauma, Chief Surgeon P. Tanskanen, MD, Senior Surgeon

J. Mäkijärvi, MD, Registrar in Surgery

T. Sorvali, MD, Registrar in Surgery

M. Ylikoski, MD, Chief Radiologist

J. Haapala, MD, Registrar in Surgery

Division of Surgery, Lahti City Hospital, Oikokatu 215100 Lahti, Finland.

Correspondence should be sent to Dr O. Korkala.

(C) 1991 British Editorial Society of Bone and Joint Surgery $0301-620 X / 91 / 1026 \$ 2.00$

J Bone Joint Surg [ Br] 1991 ; 73-B:96-9. the results of the Watson-Jones tenodesis (van der Rijt and Evans 1984) and of the Evans tenodesis (Karlsson et al 1988) deteriorate after three to seven years. According to Karlsson et al, half the results of Evans' original procedure were poor by 10 to 17 years after the operation.

We have used a modification of the Evans operation, in which the tendon is sutured to the fibular periosteum (Lauttamus, Korkala and Tanskanen 1982) instead of being fixed to itself as originally described (Evans 1953). This modification was cited by Sisk and Canale (1980) as the actual Evans procedure.

\section{PATIENTS}

Between 1977 and 1980 we operated on 42 ankles in 40 patients for chronic post-traumatic instability. The mean age of the patients was 31.7 years (range 15 to 60); 10 were female.

The initial injury could be dated in 31 cases; it occurred six months to 33 years (mean 7.7 ) prior to surgery. No previous operations had been performed on these ankles.

Pre-operatively all had a positive anterior drawer sign and/or evidence of talar tilt (Lauttamus et al 1982).

\section{METHODS}

The operation. All had the same operation (Fig. 1). The peroneus longus and brevis tendons were exposed behind the lower fibula and below the lateral malleolus. The 
original $\mathrm{J}$-shaped skin incision was later discarded in favour of two separate incisions; a $1^{\prime \prime}$ vertical incision behind the fibula at the level of the tibiofibular syndesmosis and a curved 1 " incision below the lateral malleolus. The peroneus brevis tendon was first sutured to the peroneus longus tendon, and then divided just distal to the suture. The cut tendon was dissected free from its muscle attachments and delivered into the distal incision. A tunnel $4 \mathrm{~mm}$ wide was made through the lateral malleolus in the direction of a line half-way between the anterior talofibular and the calcaneofibular ligaments. The tendon was passed proximally through the tunnel and its cut end was sutured with 1-0 chromic catgut to the periosteum of the fibula under slight tension, with the ankle in neutral position (Fig. 1). Further sutures fixed the tendon to the periosteal lining at the distal opening of the tunnel.

After skin closure, a walking plaster cast was applied and the patients were allowed to bear full weight by the second postoperative day. The plaster cast was removed after four weeks.

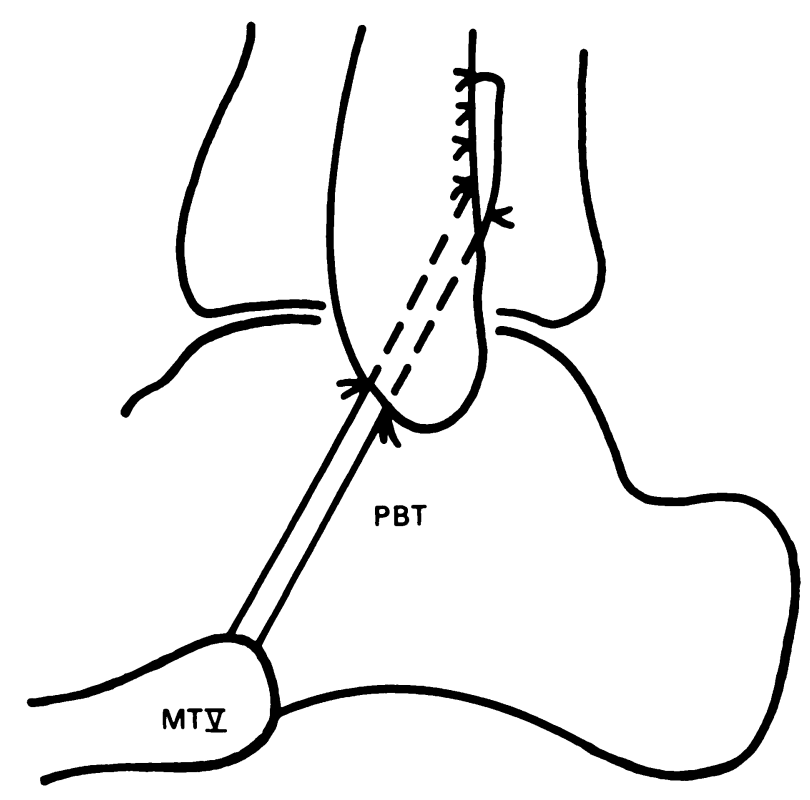

Fig. 1

The modified Evans operation. PBT, peroneus brevis tendon; MTV, fifth metatarsal.

Analysis. The present series includes 34 ankles in 32 patients already reported in a follow-up study at 24 to 35 months (Lauttamus et al 1982). Of the total of 40 patients (42 ankles), 34 patients ( 36 ankles) were available for the clinical and radiological survey. Four ankles were reviewed by questionnaire, one patient could not be reached, and one had died.

The classification of subjective criteria is that presented by Good, Jones and Livingstone (1975) and later used by Sefton et al (1979), Lauttamus et al (1982) and Karlsson et al (1988) (Table I). The clinical analysis included examination for local tenderness or swelling, range of ankle movement, and defects of skin sensation.

Lateral radiographs were taken as described by Noesberger, Hackenbruch and Müller (1977), Grace (1984) and Korkala et al (1987), but we used a stronger force to stress the joint. With the heel supported, a $20 \mathrm{~kg}$ sandbag was placed on the front of the tibia and the radiograph was taken after one minute. The anteroposterior stress radiograph was taken with the foot in equinus and manually forced into maximum inversion. Both ankles were always examined.

Table I. Grading of the postoperative result by subjective criteria (Good et al 1975)

\begin{tabular}{ll}
\hline Excellent & $\begin{array}{l}\text { Full activity, including strenuous sport. No pain, swelling or } \\
\text { giving way }\end{array}$ \\
Good & $\begin{array}{l}\text { Occasional aching only after strenuous exercise. No giving way } \\
\text { or feeling of apprehension }\end{array}$ \\
Fair & $\begin{array}{l}\text { No giving way but some apprehension, especially on rough } \\
\text { ground }\end{array}$ \\
Poor & $\begin{array}{l}\text { Recurrent instability and giving way during normal activities, } \\
\text { with episodes of pain and swelling }\end{array}$ \\
\hline
\end{tabular}

Anterior talar translation was measured on the lateral radiograph as the shortest distance between the subchondral bone plate of the talus to the posterior corner of that of the tibia. Talar tilt was measured on the anteroposterior radiograph as the angle between the tibial and talar articular surfaces.

The following criteria were taken to indicate instability: 1) an anterior talar translation (ATT) more than $6 \mathrm{~mm}, 2$ ) a difference of more than $3 \mathrm{~mm}$ between the ATT on the affected and the unaffected ankle, 3) talar tilt more than $15^{\circ}$, and 4) a difference of more than $10^{\circ}$ between the tilt on the affected and the unaffected side. One of the above criteria had to apply for the ankle to be described as unstable (Hackenbruch, Noesberger and Debrunner 1979; Grace 1984; Korkala et al 1987).

The presence or absence of osteophytes and signs of osteoarthritis were recorded.

\section{RESULTS}

By subjective criteria, 14 ankles were classified as excellent, 19 good, three fair and four poor. Three of the poor ankles had had a re-operation with one excellent, one good and one poor result. Clinical examination revealed local tenderness in two ankles, one laterally and one medially. There was a sensory defect in one case. Seven ankles had lost more than $5^{\circ}$ of extension and/or 
flexion compared to the other side. Two of these had a poor subjective result.

The radiological stress analysis showed abnormal laxity in three cases, which were subjectively graded as good, excellent and poor, respectively.

The subjective outcome appeared somewhat less good in the younger patients, but the subgroups of fair and poor results were too small for definite conclusions to be drawn.

Table II. Correlation between the functional and radiographic results for both operated and unoperated ankles. The three ankles which were re-operated (and therefore graded poor) are excluded. The objective stability and the subjective outcome appear to be independent (mean and range)

\begin{tabular}{llllll}
\hline & \multicolumn{2}{l}{ Operated ankles $(\mathrm{n}=35)$} & & \multicolumn{2}{l}{ Uninjured side $(\mathrm{n}=30)$} \\
\cline { 2 - 3 } $\begin{array}{l}\text { Subjective } \\
\text { result }\end{array}$ & $\begin{array}{l}\text { Anterior talar } \\
\text { translation }(\mathrm{mm})\end{array}$ & $\begin{array}{c}\text { Talar tilt } \\
(\text { degrees})\end{array}$ & & $\begin{array}{l}\text { Anterior talar } \\
\text { translation }(\mathrm{mm})\end{array} \begin{array}{c}\text { Talar tilt } \\
(\text { degrees })\end{array}$ \\
\hline Excellent & $4(2$ to 7$)$ & $3(0$ to 7$)$ & & $4(1$ to 6$)$ & $4(0$ to 10$)$ \\
Good & $3(2$ to 5$)$ & $3(0$ to 12$)$ & $3(2$ to 6$)$ & $4(0$ to 10$)$ \\
Fair & $4(2$ to 6$)$ & $1(1$ to 2$)$ & $5(4$ to 7$)$ & $2(0$ to 3$)$ \\
Poor & 3 & 1 & 3 & 6 \\
\hline
\end{tabular}

The results of the stress analysis showed no positive correlation with the subjective results (Table II). Nor did the presence of osteophytes or slight narrowing of the radiological joint space correlate with the subjective outcome (Table III).

\section{DISCUSSION}

We found no objective indicator of clinical outcome. Even the presence of osteophytes at the ankle was consistent with an excellent result. In fact, the only patient with restricted movements and osteophyte formation had a good functional result and a radiologically stable ankle. The ankles with local tenderness to palpation showed a talar tilt of only $1^{\circ}$, suggesting that in these the tendon may have been too tight.

In our previously published study (Lauttamus et al 1982) we recorded the status of our first 34 Evans procedures two to three years after operation. We had 31 good or excellent results, two ankles were graded as fair and one as poor. Nine to 12 years after the operation the results were much the same. These results contrast with the disappointing long-term results of Karlsson et al (1988). However, they used a different method of reconstruction which had dynamic characteristics and the possibility of the tendon sliding inside the bone tunnel. The modification of the Evans operation we use is a static reconstruction and thus a real tenodesis.

The late results of Evans operation reported by Tindall and Heaney (1976) and Cass et al (1985) were better than those of Karlsson et al (1988), but the exact method of tendon fixation used is not clear.

We did not confirm the presence of anterior or lateral instability after the Evans operation as reported by Orava et al (1983) and Karlsson et al (1988). It seems likely that the better outcome in our cases is due to the difference in technique.

Table III. The incidence of osteophytosis and osteoarthritis of the ankle related to gender $(M, F)$ and subjective result. The four cases of osteoarthritis showed only slight narrowing of the joint space

\begin{tabular}{|c|c|c|c|c|c|}
\hline \multirow[b]{2}{*}{$\begin{array}{l}\text { Subjective } \\
\text { result }\end{array}$} & \multicolumn{4}{|c|}{ Site of osteophyte } & \multirow[b]{2}{*}{ Osteoarthritis } \\
\hline & $\begin{array}{l}\text { Lateral } \\
\text { malleolus }\end{array}$ & $\begin{array}{l}\text { Medial } \\
\text { malleolus }\end{array}$ & $\begin{array}{l}\text { Anterior } \\
\text { tibia }\end{array}$ & $\begin{array}{l}\text { Anterior } \\
\text { talus }\end{array}$ & \\
\hline $\begin{array}{l}\text { Excellent } \\
n=14\end{array}$ & & $1(\mathbf{M})$ & $1(\mathrm{M})$ & & $1(M)$ \\
\hline $\begin{array}{l}\text { Good } \\
n=19\end{array}$ & $2(F) \quad 1(M)$ & $1(F)$ & & I(M) & $1(\mathrm{M}) \quad 1(\mathrm{~F})$ \\
\hline $\begin{array}{l}\text { Fair } \\
n=3\end{array}$ & & $1(\mathrm{M})$ & $1(\mathrm{M})$ & & $1(\mathrm{M})$ \\
\hline
\end{tabular}

In summary we have found the modified Evans procedure to be simple and safe. It can be performed through two small incisions and it causes no damage to the talus. Since the tendon is not acutely angulated it is not vulnerable to rupture at the sharp edges of the bony tunnel.

We dedicate this paper to our teacher, the late Leo 'Lexa' Lauttamus, MD, who performed many of the operations. The work was supported by grants from the Gyllenberg and Paulo Foundations.

No benefits in any form have been received or will be received from a commercial party related directly or indirectly to the subject of this article.

\section{REFERENCES}

Broström L. Sprained ankles: VI. Surgical treatment of "chronic" ligament ruptures. Acta Chir Scand 1966; 132:551-65.

Cass JR, Morrey BF, Katch Y, Chao EYS. Ankle instability: comparison of primary repair and delayed reconstruction after long-term follow-up study. Clin Orthop 1985; 198:110-17.

Elmslie RC. Recurrent subluxation of ankle-joint. Ann Surg 1934; $100: 364-7$.

Evans DL. Recurrent instability of the ankle joint : a method of surgical treatment. Proc R Soc Med 1953; 46:343-4.

Freeman MAR. Treatment of ruptures of the lateral ligament of the ankle. J Bone Joint Surg [Br] 1965; 47-B:661-8.

Good CJ, Jones MA, Livingstone BN. Reconstruction of the lateral ligament of the ankle. Injury 1975; 7:63-5.

Grace DL. Lateral ankle ligament injuries : inversion and anterior stress radiography. Clin Orthop 1984; 183:153-9.

Hackenbruch W, Noesberger B, Debrunner HU. Differential diagnosis of ruptures of the lateral ligaments of the ankle joint. Arch Orthop Trauma Surg 1979; 93:293-301. 
Karlsson J, Bergsten T, Lansinger O, Peterson L. Lateral instability of the ankle treated by the Evans procedure: a long-term clinical and radiological follow-up. J Bone Joint Surg [Br] 1988; 70-B 476-80.

Korkala O, Rusanen M, Jokipii P, Kytömaa J, Avikainen V. A prospective study of the treatment of severe tears of the latera ligament of the ankle. Int Orthop 1987; $11: 13-7$.

Lauttamus L, Korkala O, Tanskanen P. Lateral ligament injuries of the ankle: surgical treatment of late cases. Ann Chir Gynaecol 1982, $71: 164-7$.

Nilsonne H. Making a new ligament in ankle sprain. J Bone Joint Surg 1932; 14:380-1.

Noesberger B, Hackenbruch W, Müller ME. Diagnosis of lateral ligament lesion in the ankle joint. In: Chapchal G, ed. Injuries of the ligaments and their repair. Stuttgart: Georg Thieme, 1977: 182-3.

Orava S, Jaroma H, Weitz H, Loikkanen T, Suvela M. Radiographic instability of the ankle after Evans' repair. Acta Orthop Scand $1983 ; 54: 734-8$.
Sefton GK, George J, Fitton JM, McMullen H. Reconstruction of the anterior talofibular ligament for the treatment of the unstable ankle. J Bone Joint Surg [Br] 1979; 61-B:352-4.

Sisk TD, Canale ST. Traumatic affections of joints. In: Edmonson AS, Crenshaw AH, eds. Campbell's operative orthopaedics. 6th ed. Vol. 1. St Louis, etc: CV Mosby Co, $1980: 880-1$.

Snook GA, Chrisman OD, Wilson TC. Long-term results of the Chrisman-Snook operation for reconstruction of the lateral ligaments of the ankle. J Bone Joint Surg [Am] 1985; 67-A :1-7.

Tindall SFG, Heaney SH. Repair of the lateral ligaments of the ankle by the Evans technique. J Bone Joint Surg [Br] 1976; 58-B:133.

van der Rijt AJ, Evans GA. The long-term results of Watson-Jones tenodesis. J Bone Joint Surg [ Br] 1984; 66-B:371-5.

Watson-Jones R. Fractures and joint injuries. 4th ed. Edinburgh : E \& S Livingstone Ltd, 1952.

Weber BG, Hupfauer W. Zur behandlung der frishen fibularen bandruptur und der chronischen fibularen bandinsuffizienz. Arch Orthop Unfallchir 1969; 65:251-7. 